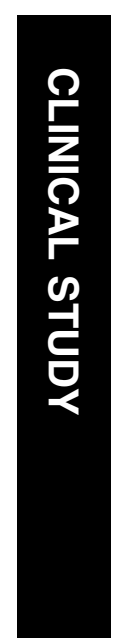

\title{
Characteristics of primary rhegmatogenous retinal detachment in Taiwan
}

${ }^{1}$ Department of

Ophthalmology, National Taiwan University Hospital, Taipei, Taiwan

${ }^{2}$ Department of Ophthalmology, Min-Sheng General Hospital, Taoyuan, Taiwan

${ }^{3}$ Department of Information Management, Leader University, Tainan, Taiwan

Correspondence:

Y-F Shih, Department of Ophthalmology,

National Taiwan University Hospital,

7 Chung-Shan South Road, Taipei, Taiwan

Tel: + 886223123456 ext 5184;

Fax: +886223412875.

E-mail:yfshih@

ha.mc.ntu.edu.tw

${ }^{4}$ These authors contributed equally to this work

Received: 11 July 2005 Accepted in revised form: 31 March 2006

Published online: 12 May 2006

This study is supported by Grant DOH91-TD-1033 from the Health Promotion Bureau, Department of Health, Executive Yuen, Republic of China

\begin{abstract}
Purpose To investigate the epidemiological characteristics and related risk factors for primary rhegmatogenous retinal detachment (RRD) in Taiwan.
\end{abstract}

Methods The case-control study was based on retrospective chart review of hospital patients treated for primary RRD from 1995 to 2001, inclusively. The preoperative fundus findings and refractive status were collected for each patient. Controls were selected from a nationwide survey of visual impairment in the adult population during the same period. Risk factors for RRD were analysed by logistic regression. A total of 1032 RRD cases and 3537 controls were enrolled for the study.

Results A pronounced bipeak pattern was evident in the age distribution for primary RRD in the third and sixth decades of life. Atrophic hole with lattice degeneration was preferential to younger (20-30 years) and highly myopic individuals $(-7.4 \pm 5 \mathrm{D})$, whereas the flap tear tended to occur in middle-aged individuals (50-60 years) and those with moderate myopia $(-4.1 \pm 5 \mathrm{D})$. The odds ratio for primary RRD with myopia, male gender, and older age ( $>40$ years) were $1.33 / \mathrm{D}, 2.15$, and 1.69 , respectively.

Conclusions Myopia is an important RRD risk factor for young Taiwanese. The increasing prevalence of myopia has predisposed the young population to RRD.

Eye (2007) 21, 1056-1061; doi:10.1038/sj.eye.6702397; published online 12 May 2006

Keywords: rhegmatogenous retinal detachment; myopia; atrophic hole; lattice degeneration; flap tear; macular hole
S-C Chou ${ }^{1,2,4}$, C-H Yang ${ }^{1,4}$, C-H Lee ${ }^{3}$, C-M Yang', T-C Ho ${ }^{1}$, J-S Huang ${ }^{1}$, C-P Lin', M-S Chen ${ }^{1}$ and Y-F Shih'

\section{Introduction}

Rhegmatogenous retinal detachment (RRD) is one of the major causes of blindness worldwide. The reported incidence of RRD is around 10-20 cases per 100000 in previous studies. ${ }^{1-15}$ Although this incidence is much lower than that for cataract and glaucoma, once RRD has occurred, visual function may be seriously impaired. Several risk factors for RRD have been identified and myopia is recognized as the most important factor in several reports. ${ }^{16,17}$

Asian populations have greater prevalence and severity of myopia than other countries in the world. The prevalence and severity of myopia have increased very rapidly over the past two decades in Taiwan. The results of a nationwide survey of myopia among Taiwanese schoolchildren in 1988 indicated that more than $84 \%$ children become myopic at 18 years old. ${ }^{18}$ The survey in 2000 revealed that the prevalence and severity of myopia increased significantly in schoolchildren relatively to the earlier survey. ${ }^{19,20}$ Several epidemiological studies of RRD were conducted in Asia. 2,3,6 However, the study populations were not as myopic as the Taiwanese. Furthermore, the characteristics of the RD were not described in detailed in these studies. The purpose of this study, therefore, was to determine the characteristics of RRD in Taiwan and to clarify the impact of the higher prevalence of myopia on RRD.

\section{Materials and methods}

\section{Study population}

Patients hospitalized at the National Taiwan University Hospital from January 1995 to December 2001, inclusively, for treatment of primary RRD were enrolled in the study. They were identified by systemic chart review. RRD was defined as a break in the retina that allowed 
vitreous fluid to enter the subretinal space and extend for at least two disc diameters. Where retinal breaks could not be identified, ultrasonic findings specific to RRD were considered sufficient for this diagnosis. Patients with newly developed RRD, whether phakic, pseudophakic, or aphakic, were enrolled in the study. Cases involving combined traction RRD, as seen in diabetes, and congenital ocular syndromes potentially causing vitreous-retinal abnormalities were excluded. In this study, patients with severe trauma history, defined as any injury which could make eyeball rupture, were also excluded.

Control subjects were selected from a nationwide survey of visual impairment in the adult population conducted in 2001. These subjects were randomly selected from the general population either in developing area or provincial cities. As our RRD cases were referred from anywhere throughout the country, we believed these controls would be representative. All subjects underwent comprehensive questionnaire and examination including slit-lamp, indirect ophthalmoscope, and autorefraction. Only individuals over 20 years of age without history of ocular surgery or trauma were enrolled.

\section{Data collection}

Information with respect to age, gender, lens status, and refractive errors of the involved eye (in spherical equivalence) was collected. The ocular fundus findings were also recorded in terms of the following characteristics: extension of the detachment area, type and location of retinal breaks, and presence of lattice degeneration and proliferative vitreoretinopathy (PVR). Retinal break types were classified as flap tear, atrophic holes without lattice degeneration, macular hole, and dialysis. When more than one type break was noted in one eye, whether it caused RRD or not, it was classified as 'combination'. All the cases were examined and operated on by retinal specialists at National Taiwan University Hospital. For controls, age, gender, and refractive status were also collected for the purpose of calculating the odds ratio for RRD risk factors. As cataract surgery itself would be a risk factor, only phakic cases and controls were subjected to this analysis.

\section{Statistical methods}

Data were analysed using Student's $t$-test, ANOVA, and the $\chi^{2}$ test. The analysis of risk factors for RRD involves a logistic regression model fitted through the stepwise selection method, one way of the methods of model selection, with the use of SPSS Base11.0 software (SPSS 11.0).

\section{Results}

A total of 1032 cases and 3537 controls were enrolled in the study (Table 1). The average age of the cases was $43 \pm 18.2$ years (range 7-94). Of the 1032 cases, 601 $(58.2 \%)$ were men and $431(41.8 \%)$ were women. Around $10.7 \%$ of RRD cases were aphakic or pseudophakic. The prevalence of myopia (>-0.5 D) in controls was $37.9 \%$, with high myopia $(\geqslant-6 \mathrm{D}) 6.9 \%$. There was no significant difference of gender and age between the cases with retinal detachment and the control subjects. For the phakic cases, there were two peaks in the age distribution curve, occurring at 20-24 and 45-59 years. For the aphakic and pseudophakic cases, only one peak was noted in the age distribution curve, occurring at 60-64 years.

\section{Characteristics of retinal detachment}

The characteristics of the retinal beaks and specific fundus findings are shown in Table 2. Around 36\% of RRD was due to flap tear, $21.1 \%$ was due to atrophic hole with lattice degeneration, and $20.2 \%$ was due to atrophic holes only. Most of the RRD was on the superior part (58.2\%). About $65 \%$ of RRD was caused by one break, with the break size less than $30^{\circ}$ in $84 \%$ of the eyes. PVR was only diagnosed in $3 \%$ of the cases and all PVRs were grade A or B. Comparing flap tear RRDs and controls, the younger cases (20-60 years old) were more myopic than controls, whereas those aged more than 61 years old showed no statistic difference in refractive errors (Table 3). In the fellow eyes, $29 \%$ of the cases had some ocular lesions that could contribute to RRD (Table 4).

The age distribution for each type of retinal break is depicted in Figure 1. Atrophic hole with lattice degeneration was associated with a higher concentration at a younger age (approximately 20-29 years) as

Table 1 Age and gender distribution for 1032 cases of primary rhegmatogenous retinal detachment and 3537 controls

\begin{tabular}{lcc}
\hline & Cases $(\mathrm{n}=1032)$ & Controls $(\mathrm{n}=3537)$ \\
\hline Sex & & \\
$\quad$ Male & $601(58.2 \%)$ & $1469(41.5 \%)$ \\
Female & $431(41.8 \%)$ & \\
Age (years) & & \\
$<20$ & $108(58.5 \%)$ \\
$20-40$ & $339(32.8 \%)$ & $1016(28.7 \%)$ \\
$41-60$ & $374(36.2 \%)$ & $1265(35.8 \%)$ \\
$>60$ & $211(20.4 \%)$ & \\
Eye & & \\
Right & $560(54.3 \%)$ & \\
Left & $472(45.7 \%)$ & \\
\hline
\end{tabular}


Table 2 Characteristics of retinal breaks and percentage in eyes with retinal detachment

\begin{tabular}{lc}
\hline Characteristics of retinal breaks & Cases $(\%)$ \\
\hline Type of retinal breaks & \\
Flap tear & $369(35.8 \%)$ \\
Atrophic hole with lattice degeneration & $218(21.1 \%)$ \\
Atrophic hole only & $208(20.2 \%)$ \\
Macular hole & $56(5.3 \%)$ \\
Dialysis & $6(0.6 \%)$ \\
Combination & $38(3.7 \%)$ \\
Not found & $137(13.3 \%)$ \\
& \\
Location of breaks & \\
Superior & $527(58.2 \%)$ \\
Inferior & $260(29.0 \%)$ \\
Mixed (superior and inferior) & $58(6.5 \%)$ \\
Macular hole & $56(6.3 \%)$ \\
Numbers of breaks & \\
One & \\
Two & $683(76.3 \%)$ \\
Three & $146(16.3 \%)$ \\
More than three & $50(5.6 \%)$ \\
& $16(1.8 \%)$ \\
Size of breaks & \\
$<30^{\circ}$ & \\
$30-90^{\circ}$ & $754(84.2 \%)$ \\
Giant tear & $63(7.0 \%)$ \\
Macular hole & $22(2.5 \%)$ \\
PVR & $56(6.3 \%)$ \\
Presence & \\
Absence & $32(3.1 \%)$ \\
\hline
\end{tabular}

aPVR: proliferative vitreoretinopathy.

Table 3 Refractive errors of flap tear cases and controls stratified by age

\begin{tabular}{lcr}
\hline Age & \multicolumn{2}{c}{ Spherical equivalence in diopter } \\
\cline { 2 - 3 } & Flap tear cases $\pm S D)$ \\
\hline $20-40^{*}$ & $-6.8 \pm 4.6$ & Controls \\
$41-60^{*}$ & $-3.9 \pm 4.6$ & $-3.0 \pm 3.3$ \\
$\geqslant 61$ & $-0.13 \pm 3.4$ & $-0.5 \pm 2.4$ \\
\end{tabular}

${ }^{*} P \ll 0.01$ by Student's $t$-test.

compared to other types of retinal breaks. When the atrophic hole only group was divided into high-grade myopic $(\geqslant-6 \mathrm{D})$ and low-grade myopic $(<-6 \mathrm{D})$ subgroups, the frequency of distribution for the former was almost similar to that for the atrophic hole with lattice degeneration group. A peak of RRD was demonstrated at 45-59 years for the low-grade myopia subgroup. The age distribution for the flap tear group also showed two distinctive patterns depending on the refractive status, with the peak occurring at 45-49 and 55-59 years of age for the high-grade myopic and
Table 4 The retinal findings in the fellow eyes

\begin{tabular}{lc}
\hline Fellow-eye status & Percentage \\
\hline Normal & 70.5 \\
Lattice degeneration & 17.7 \\
Breaks & 6.8 \\
Retinal detachment (old or new) & 4.6 \\
Phthisis or prosthesis & 0.4 \\
\hline
\end{tabular}

low-grade myopic subgroups, respectively. This distribution was inclined to older age for the macular hole group (around 50-59 years).

\section{Refractive status}

Myopia was diagnosed in $72 \%$ of phakic RRD eyes and high myopia $(\geqslant-6 \mathrm{D})$ in $62.4 \%$ of myopic eyes. Stratified by age, the mean refractive error in the younger group ( $<35$ years) with myopia was greater than $-7.0 \mathrm{D}$ (Figure 2). With increasing age, the mean refractive error (myopic diopters) declined rapidly, with some myopic shift occurring beyond 70 years of age. The mean refractive error for the macular hole group was $-9.2 \pm 5.8 \mathrm{D}$, the highest myopic refraction of all the types of retinal breaks. Odds ratio of the risk factors for nontraumatic phakic RRD are presented in Table 5. After logistic regression analysis, male, myopia, and older age ( $>40$ years) were shown to play statistically significant roles in the development of RRD.

\section{Discussion}

The most striking finding of this study was the pronounced bipeak pattern of age distribution for newly developed RRD. Even after adjustment for mean total population in Taiwan from 1995 to 2001, this distribution pattern was not particularly different, with the highest peak occurring at 20-24 years and the secondary peak at 50-54 years. As National Taiwan University Hospital is one of the few referred medical centres for RRD cases in Taiwan, the collected cases were deemed to be representative.

In previous studies, two major patterns of age distribution for RRD have been reported, ${ }^{1-15}$ a singlepeak profile occurring in older age ( $>60$ years) and a bipeak variant, with the same higher peak ( $>60$ years) and a secondary apex occurring much younger (20-30 years). Studies from United States and European countries have often reported single-peaked age distributions for RRD, ${ }^{3-15}$ whereas a bipeaked pattern was noted in the Asian analogues ${ }^{1,2,21}$ The high prevalence of myopia in Asia may account for this difference. A Japanese study published in 1990 showed 
The age distribution of RRD types

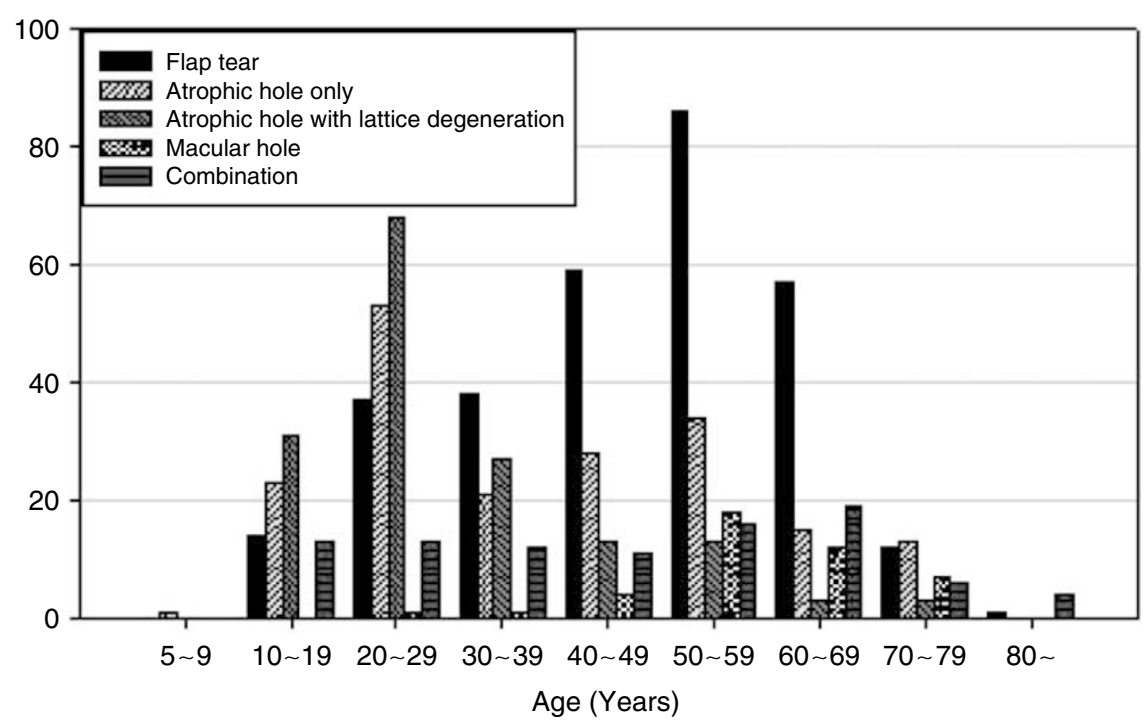

Figure 1 Age distribution for phakic RRD categorized by various types of retinal breaks.

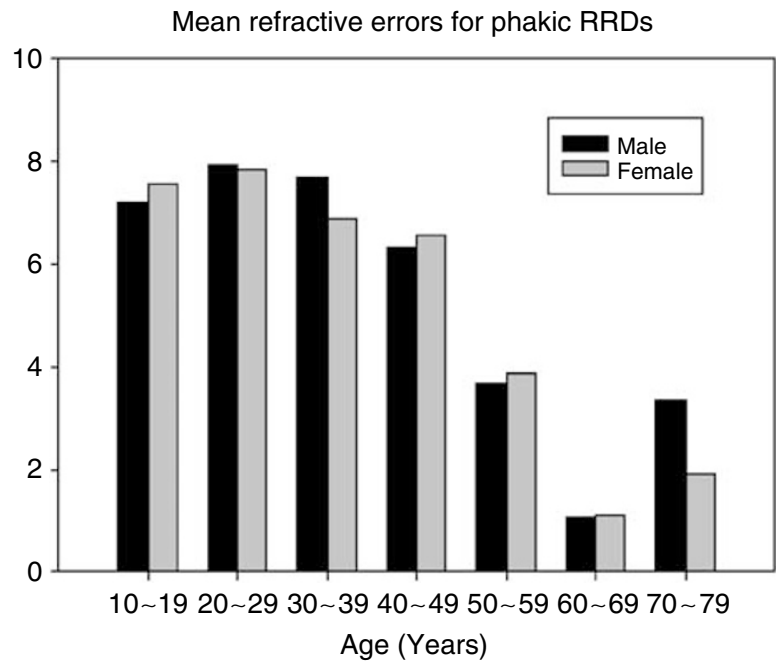

Figure 2 Mean refractive errors for all phakic RRD eyes stratified by age $(P<0.01$ from ANOVA).

that the reported prevalence of myopia at 17 years was $57 \%,{ }^{1}$ whereas in the United States the analogous prevalence at $12-17$ years was only $24 \% .{ }^{22}$ As Burton has concluded, ${ }^{23}$ this high prevalence of myopia among young Taiwanese ${ }^{18}$ may account for atrophic hole-related RRD occurring at a lower age.

The types of retinal breaks vary across different age groups. ${ }^{24}$ In our study, atrophic hole with or without lattice degeneration preferentially occurred at a younger age (peak 20-24 years). Myopia is closely associated with the formation of atrophic holes and lattice degeneration. ${ }^{23,25}$ As peripheral retinal degeneration is
Table 5 Logistic regression of risk factors for phakic rhegmatogenous retinal detachment

\begin{tabular}{lccc}
\hline Variable & OR & $95 \%$ CI for OR & P-value \\
\hline Male $^{\mathrm{a}}$ & 2.15 & $1.77-2.61$ & $<0.0001$ \\
Myopia (per diopter) $^{\mathrm{b}}$ & 1.33 & $1.29-1.36$ & $<0.0001$ \\
Age ( $>40$ years) $^{\mathrm{c}}$ & 1.69 & $1.35-2.10$ & $<0.0001$ \\
\hline
\end{tabular}

Goodness of fit, $\chi^{2}=735.98, \mathrm{df}=3 ; P$-value $<0.0001$.

$\mathrm{OR}$, odds ratio; $\mathrm{CI}$, confidence interval.

aReference: female.

${ }^{\mathrm{b}}$ Reference: nonmyopia (refractive error $<-1 \mathrm{D}$ ).

'Reference: age $\leqslant 40$ years group.

the hallmark of myopia, ${ }^{25,26}$ this finding is compatible with the greater prevalence of myopia observed in younger Taiwanese. Tillery and Lucier ${ }^{27}$ have also found that $2.8 \%$ of detachments were caused by round holes associated with lattice degeneration, $50 \%$ of their sample were under 30 years of age and $60 \%$ were myopic (between -4.0 and $-8.0 \mathrm{D}$ ). In a Japanese study, Murakami-Nagasako and $\mathrm{Ohba}^{28}$ reported that the incidence of retinal detachment associated with round holes was $21 \%$, which probably reflects the greater prevalence of myopia in their country.

In our study, flap tears preferentially occurred at an older age (peak 50-59 years) and younger flap tear RRD tended to be more myopic. Typically, flap tears are closely related to vitreous liquefaction and posterior vitreous detachment. As posterior vitreous detachment develops earlier in more myopic eyes, ${ }^{29}$ it appears reasonable to explain that flap tear-related RRD occurs earlier in these subjects. 
Macular hole occurs mainly in middle-aged and older individuals, starting in the fourth decade and peaking at 50-70 years of age. The mean refractive error for the macular hole group was $-9.2 \pm 5.8 \mathrm{D}$, the highest myopic refraction of all the types of retinal breaks. Macular hole is an uncommon cause of RRD in the United States $(0.5 \%)^{30}$ and Finland $(1.7 \%){ }^{8}$ however, it contributes to approximately $5 \%$ of nontraumatic phakic RRD in Taiwan. Compared with other countries in Asia, the incidence of macular hole-related RRD is much lower in Taiwan than in Japan $(8.9 \%)$ and China (21.1\%). ${ }^{1,31}$ Interestingly, the predominance $(73 \%)$ of females with this type of RRD, as seen in Japan ${ }^{1}$ and China, ${ }^{31}$ was also noted in the present study. Therefore, it appears reasonable to suggest racial difference or genetic factors may contribute to the development of detachment with macular hole in highly myopic eyes.

Ung et $a l^{32}$ have reported that examination of the fellow eye should be mandatory as there is a high incidence of bilateral pathology. Our results support this notion. In the fellow eye, the pathological changes that may contribute to subsequent retinal detachment were noted in $24.5 \%$ of all RRD cases and $4.6 \%$ cases were bilateral detachment. Interestingly, lattice degeneration could be found in $30 \%$ of RRD cases with atrophic holes whereas in only $2 \%$ of macular hole cases. As cases with atrophic holes or macular holes shared the same characteristic of high myopia, this interesting finding implied that lattice degeneration may be related to some genetic factors other than myopia. However, prophylactic treatment with either photocoagulation or scleral buckling of retinal tear and lattice degeneration in the fellow eye remains controversial. ${ }^{33}$

Intraocular surgery is a major risk factor in the development of RRD. As cataract surgery is the most common intraocular procedure, it is also an important risk factor for RRD. It has been estimated that $10-40 \%$ of RRD occur in eyes that have undergone cataract extraction $^{3,4,7-11}$ Our data showed a relative low percentage $(10.7 \%)$ of aphakic/pseudophakic RRD compared with the previous studies. This finding may be due, in part, to that the rapidly increasing young myopic RRD obscure the impact of cataract surgery on RRD. In addition, ECCE and phacoemulsification predominate in our study whereas ICCE was the major cataract surgery techniques in the earlier studies. With the rapidly ageing population in Taiwan, cataract surgery will become even more important as a cause of RRD in the future.

Myopia and old age were the two major risk factors for RRD as revealed in previous studies. ${ }^{16,17,23}$ Statistical analysis showed that the odds ratio for myopia and old age ( $>40$ years) in present study were 1.33/D and 1.69, respectively. As confirmed by the above analysis, myopic eyes are predisposed to atrophic and macular holes, and flap tears occur across different age groups. It has undoubtedly become the most important risk factor in RRD. The prevalence of high myopia $(>-6 \mathrm{D})$ at 18 years of age in Taiwan was around $20 \%$ in $1995 .{ }^{18}$ It is estimated that the young age incur an RRD risk at least 5.5 times higher than their nonmyopic counterparts.

The role of gender in RRD development remains obscure in many reports. ${ }^{1-16}$ In this study, males have a two-fold higher rate of RRD than females, with this tendency observed across almost all age groups. Although the incidence of ocular trauma is probably higher in males, trauma-related retinal detachments were excluded in the present study. The higher prevalence and greater myopia severity in female Taiwanese ${ }^{20}$ are obviously contradictory to this gender discrepancy. Further studies are needed to clarify the issue of whether there is another underlying sexual difference in the development of RRD.

In summary, the high prevalence of myopia in Taiwan features the characteristic bipeak age distribution of RRD. Atrophic holes, with or without lattice degeneration, is the most important cause of RRD in young myopic patients. With the rapid increase in the prevalence and severity of myopia in schoolchildren in Taiwan, an increase in RRD is expected in the near future. From the viewpoint of public health, the problem demands urgent attention to establish an appropriate eye-care system and limit its impact.

\section{References}

1 Sasaki K, Ideta H, Yonemoto J, Tanaka S, Hirose A, Oka C. Epidemiologic characteristics of rhegmatogenous retinal detachment in Kumamoto, Japan. Graefes Arch Clin Exp Ophthalmol 1995; 233: 772-776.

2 Zou H, Zhang X, Xu X, Wang X, Liu K, Ho PC. Epidemiology survey of rhegmatogenous retinal detachment in Beixinjing District, Shanghai, China. Retina 2002; 22: 294-299.

3 Li X, Beijing Rhegmatogenous Retinal Detachment Study Group. Incidence and epidemiological characteristics of rhegmatogenous retinal detachment in Beijing, China. Ophthalmology 2003; 110: 2413-2417.

4 Polkinghorne PJ, Craig JP. Northern New Zealand Rhegmatogenous Retinal Detachment Study: epidemiology and risk factors. Clin Exp Ophthalmol 2004; 32: 159-163.

5 Ivanisevic M, Bojic L, Eterovic D. Epidemiological study of nontraumatic phakic rhegmatogenous retinal detachment. Ophthalmic Res 2000; 32: 237-239.

6 Wong TY, Tielsch JM, Schein OD. Racial difference in the incidence of retinal detachment in Singapore. Arch Ophthalmol 1999; 117: 379-383.

7 Rowe JA, Erie JC, Baratz KH, Hodge DO, Gray DT, Butterfield L et al. Retinal detachment in Olmsted County, Minnesota, 1976 through 1995. Ophthalmology 1999; 106: 154-159. 
8 Laatikainen L, Tolppanen EM, Harju H. Epidemiology of rhegmatogenous retinal detachment in a Finnish population. Acta Ophthalmol (Copenhagen) 1985; 63: 59-64.

9 Wilkes SR, Beard CM, Kurland LT, Robertson DM, O'Fallon WM. The incidence of retinal detachment in Rochester, Minnesota, 1970-1978. Am J Ophthalmol 1982; 94: 670-673.

10 Haimann MH, Burton TC, Brown CK. Epidemiology of retinal detachment. Arch Ophthalmol 1982; 100: 289-292.

11 Yorston DB, Wood ML, Gilbert C. Retinal detachment in East Africa. Ophthalmology 2002; 109: 2279-2283.

12 Rosman M, Wong TY, Ong SG, Ang CL. Retinal detachment in Chinese, Malay and Indian residents in Singapore: a comparative study on risk factors, clinical presentation and surgical outcomes. Int Ophthalmol 2001; 24: 101-106.

13 Algvere PV, Jahnberg P, Textorius O. The Swedish Retinal Detachment Register. I. A database for epidemiological and clinical studies. Graefes Arch Clin Exp Ophthalmol 1999; 237: 137-144.

14 Tornquist R, Stenkula S, Tornquist P. Retinal detachment. A study of a population-based patient material in Sweden 1971-1981. I. Epidemiology. Acta Ophthalmol (Copenhagen) 1987; 65: 213-222.

15 Tornquist R, Tornquist P, Stenkula S. Retinal detachment. A study of a population-based patient material in Sweden 1971-1981. II. Pre-operative findings. Acta Ophthalmol (Copenhagen) 1987; 65: 223-230.

16 The Eye Disease Case-Control Study Group. Risk factors for idiopathic rhegmatogenous retinal detachment. Am J Epidemiol 1993; 137: 749-757.

17 Austin KL, Palmer JR, Seddon JM, Glynn RJ, Rosenberg L, Gragoudas ES et al. Case-control study of idiopathic retinal detachment. Int J Epidemiol 1990; 19: 1045-1050.

18 Lin LL, Shih YF, Tsai CB, Chen CJ, Lee LA, Hung PT et al. Epidemiologic study of ocular refraction among schoolchildren in Taiwan in 1995. Optom Vis Sci 1999; 76: 275-281.

19 Lin LL, Shih YF, Hsiao CK, Chen CJ, Lee LA, Hung PT. Epidemiologic study of the prevalence and severity of myopia among schoolchildren in Taiwan in 2000. J Formos Med Assoc 2001; 100: 684-691.

20 Lin LL, Shih YF, Hsiao CK, Chen CJ. Prevalence of myopia in Taiwanese schoolchildren: 1983 to 2000. Ann Acad Med Singapore 2004; 33: 27-33.
21 Ogawa A, Tanaka M. The relationship between refractive errors and retinal detachment - analysis of 1,166 retinal detachment cases. Jpn J Ophthalmol 1988; 32: 310-315.

22 Sperduto RD, Seigel D, Roberts J, Rowland M. Prevalence of myopia in the United States. Arch Ophthalmol 1983; 101: 405-407.

23 Burton TC. The influence of refractive error and lattice degeneration on the incidence of retinal detachment. Trans Am Ophthalmol Soc 1989; 87: 143-155.

24 Uemura A, Ohba N. Age of onset of rhegmatogenous retinal detachment analyzed by Weibull distribution function. Nippon Ganka Gakkai Zassh 1996; 100: 624-627.

25 Lewis H. Peripheral retinal degenerations and the risk of retinal detachment. Am J Ophthalmol 2003; 136: 155-160.

26 Celorio JM, Pruett RC. Prevalence of lattice degeneration and its relation to axial length in severe myopia. Am J Ophthalmol 1991; 111: 20-23.

27 Tillery WV, Lucier AC. Round atrophic holes in lattice degeneration - an important cause of phakic retinal detachment. Trans Am Acad Ophthalmol Otolaryngol 1976; 81: 509-518.

28 Murakami-Nagasako F, Ohba N. Phakic retinal detachment associated with atrophic hole of lattice degeneration of the retina. Graefe's Arch Clin Exp Ophthalmol 1983; 220: 175-178.

29 Sasaki K, Ideta H, Yonemoto J, Tanaka S, Hirose A, Oka C. Risk of retinal detachment in patients with lattice degeneration. Jpn J Ophthalmol 1998; 42: 308-313.

30 Margherio RR, Schepens CL. Macular breaks: diagnosis, etiology and observations. Am J Ophthalmol 1972; 74: 219-232.

31 Zhang C, Hu C. High incidence of retinal detachment secondary to macular hole in a Chinese population. Am J Ophthalmol 1982; 94: 817-819.

32 Ung T, Comer MB, Ang AJS, Sherad R, Lee C, Poulson AV et al. Clinical features and surgical management of retinal detachment secondary to round retinal holes. Eye 2005; 19: 665-669.

33 Mastropasqua L, Carpineto P, Ciancaglini M, Falconio G, Gallenga PE. Treatment of retinal tears and lattice degenerations in fellow eyes in high risk patients suffering retinal detachment: a prospective study. $\mathrm{Br} J$ Ophthalmol 1999; 83: 1046-1049. 